\title{
Formulation, optimization and evaluation of mucoadhesive microspheres of captopril
}

\author{
Amitha SHETTY ${ }^{1 *}(\mathbb{D})$, Panneer SELVAM ${ }^{2}(\mathbb{D})$, Smitha SHETTY 3 (D), Chrishma SHALOMITH ${ }^{3}(\mathbb{D}$ \\ 1 Department of Pharmaceutics, Research Scholar of Pacific Academy of Higher Education, Pacific University, \\ Udaipur, India. \\ 2 Department of Pharmaceutical Chemistry, Principal of Saraswati College of Pharmacy, Uttar Pradesh, India \\ 3 Department of Pharmaceutics, Shree Devi College of Pharmacy, Mangalore, Karnataka, India. \\ * Corresponding Author. E-mail: amitha18pharma@gmail.com (A.S.); Tel. +91-944-959 3585.
}

Received: 15 April 2019 / Revised: 06 June 2019 / Accepted: 07 June 2019

\begin{abstract}
The objective of the present study was to develop mucoadhesive microspheres of captopril in order to achieve extended retention in upper gastro intestinal tract to enhance absorption and bioavailability. The microspheres were prepared by emulsification method using different ratio of sodium alginate with captopril by cross-linking with calcium chloride. Fourier-transform infrared spectroscopy study shows that captopril and other excipients are compatible with each other. The effects of polymers concentration on drug release profile were investigated. Response surface methodology was applied to systemically optimize the drug release profile. Polymer to drug ratio and stirring speed were selected as independent variables. Drug entrapment efficiency, percentage mucoadhesive and in vitro drug release after 6 hours were selected as dependent variables. Obtained microspheres were subjected to different evaluation parameters such as percentage yield, particle size analysis, drug entrapment efficiency, percentage mucoadhesive, in vitro drug release, drug release kinetics and scanning electron microscopy. The optimized formulation (MM10) showed satisfactory drug entrapment efficiency of $80.34 \pm 1.8 \%$, percentage mucoadhesive of $95.75 \pm 1.2$ and percentage drug release after 6 hours of $26.08 \pm 0.45 \%$. Scanning electron microscopy analysis revealed that particles were spherical with smooth surface. Particles were free flowing with average particle size of $51.43 \mu \mathrm{m}$. Better results were observed from optimized mucoadhesive microspheres of captopril, thereby improving the bioavailability due to prolong release of drug in stomach.
\end{abstract}

KEYWORDS: Response surface methodology; emulsification method; optimization; captopril; dependent and independent variables; mucoadhesive; microspheres.

\section{INTRODUCTION}

Various diseases, such as hypertension, rheumatoid arthritis and angina pectoris show circadian rhythm where these diseases show critical conditions during early hours of the day such as inflammations associated with morning stiffness, asthmaand heart attack in early hours of the day. For such diseases conventional drug delivery systems are inappropriate, as they cannot be administered just before the symptoms are worsened, because during this time, the patients are asleep. Such diseases require rationale therapy where drug is released from the dosage forms when the symptoms are worsen particularly during early hours [1].

Hypertension is a chronic medical condition in which the blood pressure in the arteries is elevated. Blood pressures are subjected to circadian rhythms such as vascular reactivity and capillary resistances are higher during day time whereas platelet aggregation is increased in the morning, leading to a state of relative hypercoagulability of the blood. The peak blood pressure is during 4 am and noon. These changes in blood pressure correspond to morning activation in catecholamines, renin and angiotensin [2].

Captopril is well absorbed from the proximal small intestine; approximately $70 \%$ is absorbed in healthy fasting subjects. Captopril is a structural derivative of the amino acid proline and it is, therefore, likely that the drug is absorbed from the small intestine by an active transport process. Captopril has a narrow absorption window which limits its absorption from other parts of intestine. Short biological half life of 1-2 hours is one of the most important drawback of captopril. Therefore, the development of a once-daily captopril oral formulation would be a significant advantage for patient compliance [3,4].

How to cite this article: Shetty A, Selvam P, Shetty S, Shalomith C. Formulation, optimization and evaluation of mucoadhesive microspheres of captopril. J Res Pharm. 2019; 23(5): 860-872. 
Marketed captopril could not able to release drug in the early morning hours when the symptoms of diseases were at peak level in the case of heart attack patients.

To satisfy these conditions, mucoadhesive concept was applied to formulate captopril microspheres, to increase gastric residence of dosage form.

\section{RESULTS AND DISCUSSION}

\subsection{Compatibility studies}

The IR spectra of the combination of captopril and sodium alginate and optimized formulation (MM10) were compared with the standard spectrum of pure drug captopril and the characteristic peaks associated with specific functional groups and bonds of the molecule and their presence/ absence were noted.

The prominent peaks associated with $\mathrm{C}-\mathrm{H}, \mathrm{S}-\mathrm{H}, \mathrm{C}=\mathrm{O}-\mathrm{COOH}, \mathrm{C}=\mathrm{O}$ Amide, C-O Stretching and C-N stretching were analysed. The range of peak values were found to be the same indicating that there were no interaction of captopril with different polymers confirming the stability of drug in the formulations.

The FTIR spectrum of captopril, captopril and sodium alginate and optimized formulation (MM10) are shown in the Figure 1.

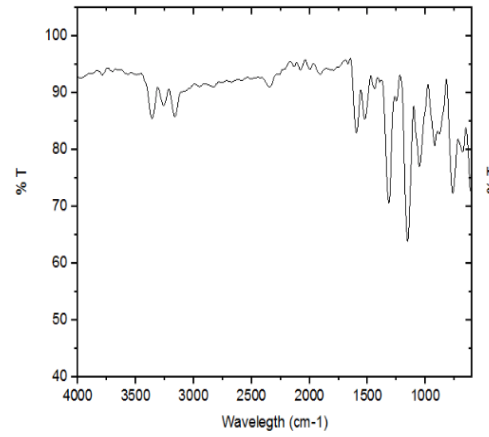

A

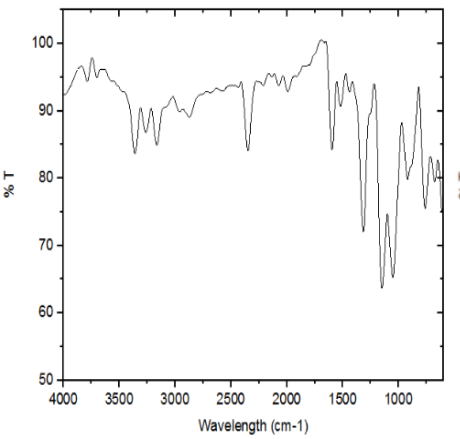

B

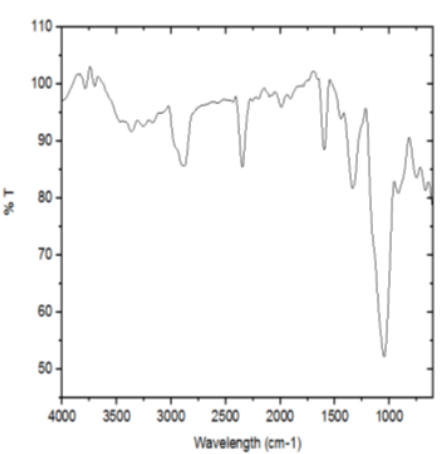

C

Figure 1. FTIR spectra of pure drug captopril (A), mixture of captopril and sodium alginate (B) and optimized formulation (MM10) (C).

\subsection{Preliminary trial batches}

Several preliminary trial batches were undertaken for various proportions of captopril and sodium alginate for qualitative and quantitative determination of microsphere characteristics. It was found that sodium alginate microspheres showed desirable yield, drug content, entrapment efficiency, percentage mucoadhesive and adequate drug release characteristics as shown in Tables 1 and 2.

Table 1. Evaluation parameters of preliminary batches.

\begin{tabular}{cccccccc}
\hline $\begin{array}{c}\text { Batch } \\
\text { code }\end{array}$ & $\begin{array}{c}\text { Percentage } \\
\text { yield }\end{array}$ & $\begin{array}{c}\text { Particle size } \\
(\boldsymbol{\mu m})\end{array}$ & $\begin{array}{c}\text { Bulk } \\
\text { density }\end{array}$ & $\begin{array}{c}\text { Tapped } \\
\text { density }\end{array}$ & $\begin{array}{c}\text { Hausner's } \\
\text { ratio }\end{array}$ & $\begin{array}{c}\text { Carr's } \\
\text { index }\end{array}$ & $\begin{array}{c}\text { Angle of } \\
\text { repose }\end{array}$ \\
\hline M1 & $71.5 \pm 1.17$ & $52.9 \pm 3.43$ & $0.79 \pm 0.27$ & $0.85 \pm 0.43$ & $1.07 \pm 0.03$ & $7.05 \pm 0.45$ & $19.88 \pm 0.31$ \\
M2 & $79.0 \pm 1.43$ & $61.5 \pm 3.05$ & $0.85 \pm 0.37$ & $1.05 \pm 0.23$ & $1.23 \pm 0.37$ & $19.04 \pm 1.43$ & $20.04 \pm 0.15$ \\
M3 & $87.9 \pm 1.65$ & $86.3 \pm 3.09$ & $0.95 \pm 0.26$ & $1.12 \pm 0.31$ & $1.17 \pm 0.83$ & $15.17 \pm 0.23$ & $23.27 \pm 0.21$ \\
M4 & $88.8 \pm 1.13$ & $87.9 \pm 3.83$ & $0.97 \pm 0.74$ & $1.19 \pm 0.55$ & $1.22 \pm 0.19$ & $18.48 \pm 0.65$ & $25.81 \pm 0.27$ \\
\hline
\end{tabular}

*All values represent mean \pm SD; $(n=3)$. SD: Standard deviation.

Table 2. Evaluation parameters of preliminary batches.

\begin{tabular}{cccc}
\hline $\begin{array}{c}\text { Batch } \\
\text { code }\end{array}$ & $\begin{array}{c}\text { Percentage } \\
\text { mucoadhesive }\end{array}$ & $\begin{array}{c}\text { Percentage entrapment } \\
\text { efficiency }\end{array}$ & $\begin{array}{c}\text { Percentage drug release after 6 } \\
\text { hours }\end{array}$ \\
\hline M1 & $76.84 \pm 1.5$ & $57.54 \pm 1.1$ & $48.80 \pm 0.37$ \\
M2 & $84.45 \pm 1.8$ & $68.59 \pm 1.4$ & $36.67 \pm 0.88$ \\
M3 & $91.09 \pm 1.4$ & $72.54 \pm 1.0$ & $31.25 \pm 0.28$ \\
M4 & $91.80 \pm 1.6$ & $60.00 \pm 1.6$ & $21.26 \pm 0.74$ \\
\hline
\end{tabular}

*All values represent mean \pm SD; $(n=3)$. SD: Standard deviation. 
It was observed that as the concentration of sodium alginate was increased from $1 \%$ to $4 \%$ the percentage yield of microspheres increased from $71.50 \%$ to $88.86 \%$, particle size increased from $52.98 \mu \mathrm{m}$ to $87.93 \mu \mathrm{m}$, percentage mucoadhesive increased from $76.84 \%$ to $91.80 \%$ and entrapment efficiency increased from $57.54 \%$ to $72.54 \%$ for $3 \%$ sodium alginate and further decreased to $60 \%$ as concentration of sodium alginate increased to $4 \%$. Percentage drug release after 6 hours decreased from $52.43 \%$ to $38.34 \%$ as shown in Figure 2. For the formulation 1:3, Carr's index and Hausner's ratio were found to be within the limits i.e. Carr's index was less than 25 and Hausner's ratio was found to be less than 1.25 indicating good flow properties. Hence drug: polymer ratio 1:3 at $1500 \mathrm{rpm}$ was selected for optimization.

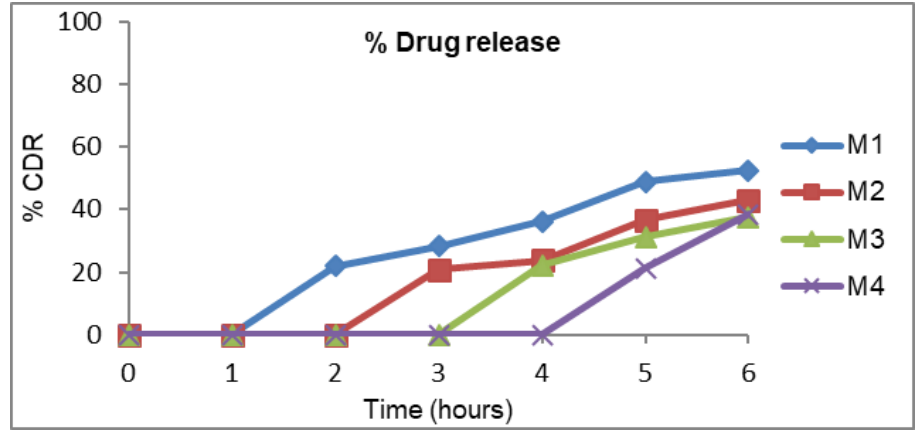

Figure 2. Percentage drug release of preliminary batches (M1-M4).

All values represent mean $\pm S D ;(n=3)$. SD: Standard deviation.

\subsection{Captopril mucoadhesive microspheres subjecting to optimization}

From the results of the preliminary trial batches of captopril mucoadhesive microspheres, the drug: polymer ratio 1:3 at $1500 \mathrm{rpm}$ was selected for optimization. Nine different formulations were obtained coded as MM1-MM9.

\subsection{Evaluation of captopril mucoadhesive microspheres subjected to optimization (MM1-MM9)}

\subsubsection{Percentage yield}

The effect of sodium alginate concentration and stirring speed was determined. The percentage yield increased from $80.40 \%$ to $94.65 \%$ with increase in sodium alginate concentration and increase in stirring speed from 1000 to $2000 \mathrm{rpm}$. Decrease in the polymer concentration has resulted in a decrease in the percentage yield. This may be due to the fact that as the concentration of polymer decreases the quantity of polymer becomes less to cover drug particles completely. As more amount of polymer is available, therefore as the sodium alginate concentration increases percentage yield increases (Table 3) [5].

\subsubsection{Micromeritic studies}

\section{Particle size analysis}

The particle size decreased from 89.07 to $48.47 \mu \mathrm{m}$ with increase in speed from 1000 to $2000 \mathrm{rpm}$ at $3 \%$ concentration of sodium alginate indicating that as the stirring speed increases particle size decreases. The particle size increased from 49.84 to $87.85 \mu \mathrm{m}$ with increase in concentration of sodium alginate at $1500 \mathrm{rpm}$ indicating that as the concentration of sodium alginate increases particle size increases (Table 3). The result indicates that as the polymer concentration increase it results in high viscosity of polymer solution thereby increasing the size of the particle. As the polymer concentration increases, there is an increase in the frequency of collision, which results in the fusion of semi-formed particles and production of an overall increase in the size of the microspheres. The increase in stirring speed produced higher energy, which decreased the size, and thus produced smaller microspheres [6].

\section{Bulk density, Tapped density, Carr's Compressibility Index, Hausner's ratio and Angle of Repose}

The bulk density, tapped density and Hausner's ratio of formulation MM1 to MM9 ranges from $0.82 \pm 0.04$ to $1.28 \pm 0.67,0.89 \pm 0.85$ to $1.58 \pm 0.92$ and $1.07 \pm 0.23$ to $1.32 \pm 0.37$ respectively. The Carr's compressibility index ranges between $6.73 \pm 0.30$ to $24.63 \pm 0.07 \%$. The angle of repose ranges from $21.59 \pm 0.43$ to $28.27 \pm 0.65$ (Table 3). The Carr's index and angle of repose values indicated excellent flow properties of microspheres [7]. 
Table 3. Evaluation parameters of the optimized formulations.

\begin{tabular}{cccccccc}
\hline $\begin{array}{c}\text { Batch } \\
\text { code }\end{array}$ & $\begin{array}{c}\text { Percentage } \\
\text { yield }\end{array}$ & $\begin{array}{c}\text { Particle } \\
\text { size }(\boldsymbol{\mu m})\end{array}$ & $\begin{array}{c}\text { Bulk } \\
\text { density }\end{array}$ & $\begin{array}{c}\text { Tapped } \\
\text { density }\end{array}$ & $\begin{array}{c}\text { Hausner's } \\
\text { ratio }\end{array}$ & $\begin{array}{c}\text { Carr's } \\
\text { index }\end{array}$ & $\begin{array}{c}\text { Angle of } \\
\text { repose }\end{array}$ \\
\hline MM 1 & $86.9 \pm 1.05$ & $81.2 \pm 3.50$ & $0.93 \pm 0.02$ & $1.10 \pm 0.83$ & $1.18 \pm 0.19$ & $15.45 \pm 0.11$ & $24.31 \pm 0.55$ \\
MM 2 & $80.4 \pm 1.07$ & $49.8 \pm 3.30$ & $0.82 \pm 0.04$ & $0.89 \pm 0.85$ & $1.08 \pm 0.21$ & $7.86 \pm 0.07$ & $22.80 \pm 0.31$ \\
MM 3 & $92.7 \pm 1.05$ & $87.8 \pm 3.30$ & $1.27 \pm 0.80$ & $1.56 \pm 0.84$ & $1.22 \pm 0.24$ & $18.58 \pm 0.11$ & $23.07 \pm 0.23$ \\
MM 4 & $89.2 \pm 1.07$ & $48.4 \pm 3.65$ & $1.08 \pm 0.69$ & $1.28 \pm 0.94$ & $1.18 \pm 0.36$ & $15.62 \pm 0.10$ & $21.59 \pm 0.43$ \\
MM 5 & $91.7 \pm 1.02$ & $56.5 \pm 4.45$ & $1.28 \pm 0.67$ & $1.58 \pm 0.92$ & $1.23 \pm 0.34$ & $18.98 \pm 0.02$ & $23.15 \pm 0.45$ \\
MM 6 & $85.8 \pm 1.10$ & $46.9 \pm 3.43$ & $1.04 \pm 0.55$ & $1.38 \pm 0.30$ & $1.32 \pm 0.37$ & $24.63 \pm 0.07$ & $28.27 \pm 0.65$ \\
MM 7 & $85.5 \pm 1.11$ & $89.0 \pm 3.23$ & $0.97 \pm 0.20$ & $1.04 \pm 0.37$ & $1.07 \pm 0.23$ & $6.73 \pm 0.30$ & $25.69 \pm 0.55$ \\
MM 8 & $78.0 \pm 1.07$ & $82.8 \pm 3.31$ & $1.03 \pm 0.22$ & $1.25 \pm 0.39$ & $1.21 \pm 0.25$ & $17.60 \pm 0.50$ & $22.90 \pm 0.80$ \\
MM 9 & $94.6 \pm 1.11$ & $90.9 \pm 2.55$ & $0.84 \pm 0.24$ & $0.92 \pm 0.92$ & $1.09 \pm 0.36$ & $8.96 \pm 0.31$ & $27.21 \pm 0.21$ \\
\hline
\end{tabular}

*All values represent mean \pm SD; $(n=3)$. SD: Standard deviation.

\subsubsection{Percentage mucoadhesive}

To ensure the adhesion of micropsheres to the mucosa, mucoadhesion studies were carried out for a prolonged period of time. The microspheres containing sodium alginate showed good mucoadhesive property for more than 3 hours. (Table 4). As the stirring speed increases, the percentage mucoadhesive decreases, which may be due to chnage in the particle size that affects mucoadhesion. Whereas as the polymer concentration increases, the percentage mucoadhesion also increases. The mucoadhesive property of these particles resulted in prolonged retention in the gastric mucosa.

\subsubsection{Drug entrapment efficiency}

All the formulations showed good percentage entrapment efficiency with maximum up to $85.12 \pm 0.2 \%$ as shown in Table 4. The percentage entrapment efficiency decreased from $75.56 \pm 2.1$ to $70.78 \pm 2.1 \%$ with increase in speed from 1000 to $2000 \mathrm{rpm}$ at $3 \%$ concentration of sodium alginate as well as decreased from $80.34 \pm 1.2$ to $67.59 \pm 1.5 \%$ with increase in concentration of sodium alginate at $1500 \mathrm{rpm}$ indicating that as the stirring speed and concentration of sodium alginate increases percentage entrapment efficiency decreases.

The method used for the preparation of microspheres may be the reason for the high drug entrapment efficiency. The calcium chloride solution was merged with the internal phase of alginate-containing drug by use of methanol which resulted in the formation of gel instantaneously with entrapment of the drug in the planar two-dimensional lattice of the cross-linked alginate to produce the 'eggbox' structure. This can account for the quick hardening of the gel preventing the escape of acyclovir back into the aqueous phase of the emulsion [5].

\subsubsection{In vitro drug release studies}

It was observed that as the concentration of sodium alginate was increased, the percentage drug release of captopril decreased. (Table 4). The decrease in drug release may be attributed to the increase in the extent of swelling and the gel layer thickness that acted as a barrier for the penetration medium, thereby retarding the diffusion of captopril from the swollen alginate matrix. Figure 3 depicts the plot of cumulative percentage drug release $\mathrm{v} / \mathrm{s}$ time graph for the nine formulations.

Table 4. Evaluation parameters of the optimized formulations.

\begin{tabular}{cccc}
\hline $\begin{array}{l}\text { Batch } \\
\text { code }\end{array}$ & $\begin{array}{c}\text { Percentage } \\
\text { mucoadhesive }\end{array}$ & $\begin{array}{c}\text { Percentage entrapment } \\
\text { efficiency }\end{array}$ & $\begin{array}{c}\text { Percentage drug release after 6 } \\
\text { hours }\end{array}$ \\
\hline MM 1 & $91.99 \pm 1.9$ & $72.65 \pm 1.4$ & $35.68 \pm 0.19$ \\
MM 2 & $92.92 \pm 2.1$ & $80.34 \pm 1.2$ & $44.89 \pm 0.21$ \\
MM 3 & $95.16 \pm 1.0$ & $67.59 \pm 1.5$ & $23.54 \pm 0.10$ \\
MM 4 & $93.02 \pm 2.3$ & $70.78 \pm 2.1$ & $36.97 \pm 0.23$ \\
MM 5 & $93.71 \pm 0.5$ & $66.00 \pm 1.2$ & $36.28 \pm 0.05$ \\
MM 6 & $96.21 \pm 1.4$ & $74.76 \pm 1.1$ & $54.65 \pm 0.14$ \\
MM 7 & $93.11 \pm 2.6$ & $75.56 \pm 2.1$ & $34.54 \pm 0.26$ \\
MM 8 & $92.98 \pm 1.0$ & $85.12 \pm 0.2$ & $29.29 \pm 0.10$ \\
MM 9 & $97.07 \pm 1.9$ & $69.58 \pm 1.9$ & $28.35 \pm 0.19$ \\
\hline
\end{tabular}

*All values represent mean \pm SD; $(n=3)$. SD: Standard deviation. 


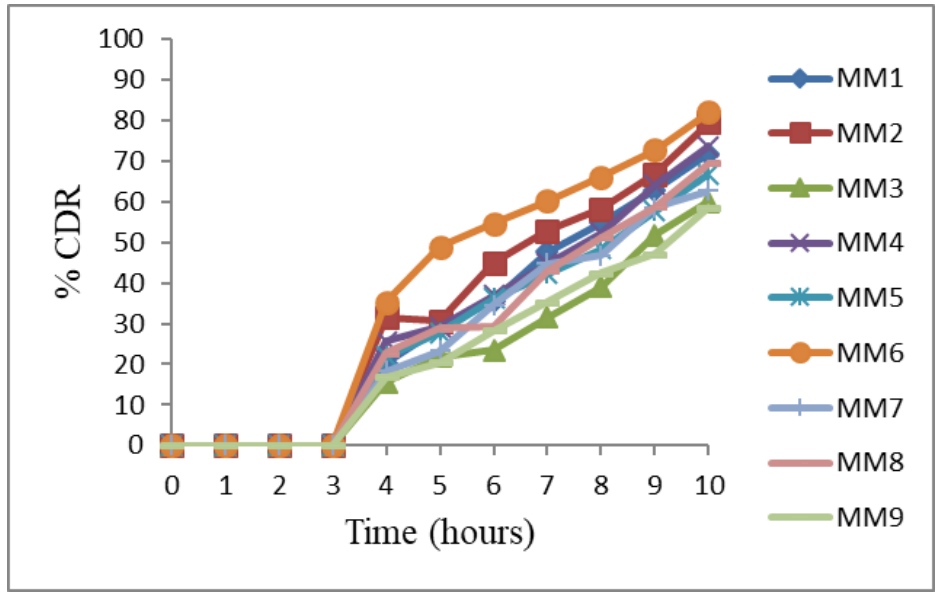

Figure 3. Percentage drug release of optimized batches (MM1-MM9).

All values represent mean \pm SD; $(n=3)$. SD: Standard deviation.

\subsection{Data analysis and model validation}

\subsubsection{Fitting of data to the model, Contour and three-dimensional (3D) response surface plot analysis}

All the response variables were observed experimentally for 9 runs as proposed by the central composite design and were fitted to run design chart. After elimination of non-significant coefficients, following correlations were obtained for response variables in terms of coded factors:

Percentage mucoadhesive: $\mathrm{Y}_{1}=+95.97+1.24 \mathrm{~A}-0.2117 \mathrm{~B}+0.9425 \mathrm{AB}-0.6150 \mathrm{~A}^{2}+0.93 \mathrm{~B}^{2}$

Percentage entrapment efficiency: $\mathrm{Y}_{2}=+74.46-1.39 \mathrm{~A}-0.2167 \mathrm{~B}+5.42 \mathrm{AB}+0.9017 \mathrm{~A}^{2}+1.90 \mathrm{~B}^{2}$

Percentage drug release at 6 hours: $\mathrm{Y}_{3}=+26.86-2.84 \mathrm{~A}+1.22 \mathrm{~B}-1.87 \mathrm{AB}-2.56 \mathrm{~A}^{2}+3.01 \mathrm{~B}^{2}$

Where $\mathrm{A}$ is the sodium alginate concentration and $\mathrm{B}$ is stirring speed.

The above model equations carry factors along with coefficients (positive/negative) which quantifies response values. A negative sign indicates antagonistic effect whereas positive sign of coefficient indicates synergistic effect.

All the polynomial equations were found to be statistically significant $(p<0.01)$, as determined using ANOVA as per the provision of design expert software. The "F-value lack of fit" of 3.01 implies that the F value is not significant relative to the pure error. Non-significant lack of fit is good, and the model is fit.

Equation (1) suggests that the factor A have a positive effect whereas factor B has a negative effect on the percentage mucoadhesive of the dosage forms. As the concentration of sodium alginate increased the percentage mucoadhesive also increased whereas as the stirring speed increased the mucoadhesive decreased. The 3D response surface plot, Figure 4a is used to see the impact of independent variables and was found that the percentage mucoadhesive increased with increase in the concentration of sodium alginate and decreased with increase in stirring speed. This is also supported by the contour plot as shown in Figure $4 \mathrm{~b}$.

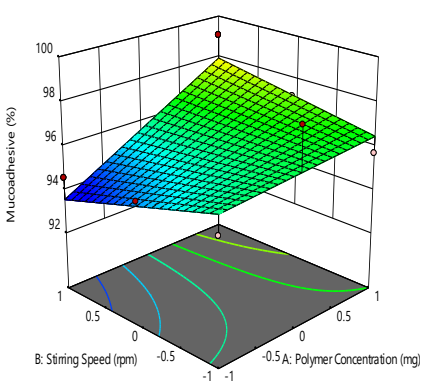

A

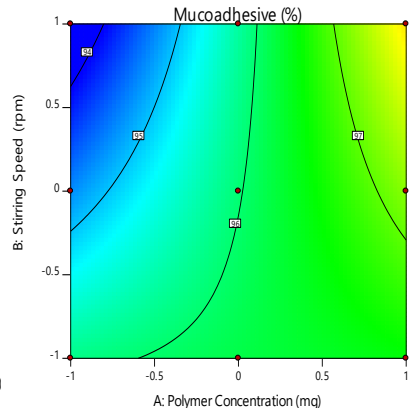

B

Figure 4: Percentage mucoadhesive 3D surface response plot (A) and contour plot (B). 
Equation (2) suggests that the factor A as well as factor B have a negative effect on the percentage entrapment efficiency of the dosage forms. As the concentration of sodium alginate and stirring speed increased, the percentage entrapment efficiency decreased. The 3D response surface plot, Figure $5 \mathrm{a}$ is used to see the impact of independent variables and was found that the percentage entrapment efficiency decreased with increase in the concentration of sodium alginate and stirring speed. This is also supported by the contour plot as shown in Figure 5b.

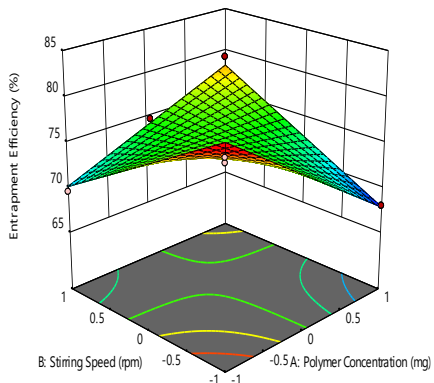

A

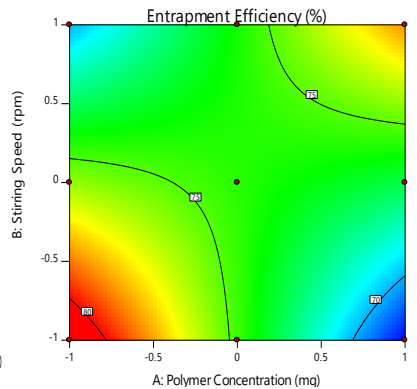

B

Figure 5. Percentage entrapment efficiency 3D surface response plot (A) and contour plot (B).

Equation (3) suggests that the factors A have negative effect whereas factor B have a positive effect on percentage drug release after 6 hours. As the concentration of the polymer increased percentage drug release after 6 hours gets decreased significantly whereas as the stirring speed increased percentage drug release after 6 hours gets increased. To visualize the impact of changing variables, the response surface plot Figure 6a and contour plot Figure $6 \mathrm{~b}$ were used.

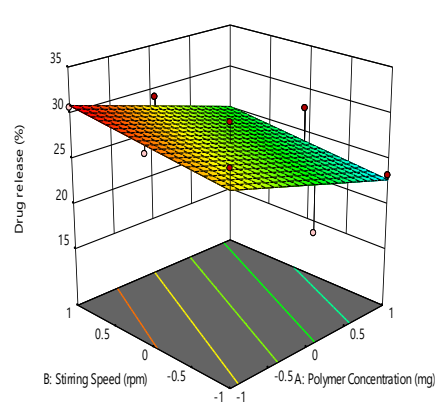

A

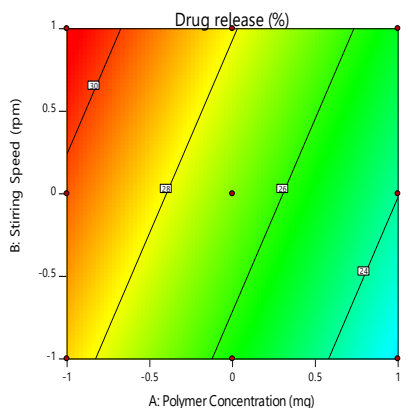

B

Figure 6. Percentage drug release 3D surface response plot (A) and contour plot (B) after 6 hours.

\subsection{Optimization}

To generate an optimum formulation, numerical optimization technique using the desirability function approach was employed. Suitable levels of constraints (Target) were chosen to achieve desired responses of the formulation. The desirable ranges of responses were restricted to percentage mucoadhesive at $95 \%$, percentage entrapment efficiency at $82 \%$ and percentage drug release after 6 hours at $25 \%$ as shown in Table 5 as per the software. On analyzing various response variables and comprehensive evaluation of feasibility of exhaustive grid search, the following combination of variables was suggested by the software, sodium alginate concentration $=3 \%$ and stirring speed $=1250(\mathrm{rpm})$.

\subsection{Evaluation of the optimized captopril mucoadhesive microspheres}

Prepared optimized captopril mucoadhesive microspheres were evaluated and the percentage yield of microsphere was found to be $78.98 \pm 1.9 \%$ and the particle size was $51.43 \pm 3.43 \mu \mathrm{m}$. The bulk density, tapped density and Hausner's ratio was $0.85 \pm 0.84,0.91 \pm 0.26$ and $1.07 \pm 0.90$ respectively. The Carr's compressibility index and angle of repose were found to be $6.59 \pm 0.38 \%$ and $21.09 \pm 0.43$ respectively indicating excellent flow properties of microspheres.

The percentage mucoadhesive and drug entrapment efficiency were observed as $95.75 \%$ and $80.34 \%$ respectively. The in vitro drug release study was found to be $26.08 \%$ after 6 hours. Table 6 lists the predicted 
and experimental values of all the response variables, and the percentage error. Upon comparison of the observed responses with that of the anticipated responses, the mean of percentage error was found to be 0.82 . Thus, the low magnitudes of error indicated excellent fit of model.

Table 5. Criterion for numerical optimization.

\begin{tabular}{|c|c|c|c|c|c|c|}
\hline Parameters & Goal & Lower limit & $\begin{array}{l}\text { Upper } \\
\text { limit }\end{array}$ & $\begin{array}{l}\text { Lower } \\
\text { weight }\end{array}$ & $\begin{array}{l}\text { Upper } \\
\text { weight }\end{array}$ & Importance \\
\hline $\begin{array}{l}\text { A: Polymer } \\
\text { Concentration }(\% \mathrm{w} / \mathrm{v})\end{array}$ & Is in range & -1 & 1 & 1 & 1 & 1 \\
\hline B: Stirring speed (rpm) & Is in range & -1 & 1 & 1 & 1 & 1 \\
\hline $\begin{array}{l}Y_{1} \text { : Percentage } \\
\text { mucoadhesive }\end{array}$ & Target=95 & 91 & 97 & 1 & 1 & 1 \\
\hline $\begin{array}{l}Y_{2}: \text { Percentage } \\
\text { entrapment efficiency }\end{array}$ & Target $=82$ & 66 & 85 & 1 & 1 & 1 \\
\hline $\begin{array}{l}Y_{3} \text { : Percentage drug } \\
\text { release after } 6 \text { hours }\end{array}$ & Target $=25$ & 23 & 54 & 1 & 1 & 1 \\
\hline \multirow[t]{2}{*}{$\begin{array}{l}\text { MM10 } \\
\text { (optimized) }\end{array}$} & $\begin{array}{c}\mathrm{CPT} \\
\text { concentration } \\
(\%) \\
\end{array}$ & $\begin{array}{c}\text { Sodium alginate } \\
\text { concentration } \\
(\%)\end{array}$ & $\begin{array}{c}\text { Stirring } \\
\text { speed (rpm) }\end{array}$ & & & \\
\hline & 1 & 3 & 1000 & & & \\
\hline
\end{tabular}

Table 6. Comparison of experimental results with predicted responses of optimized formulation.

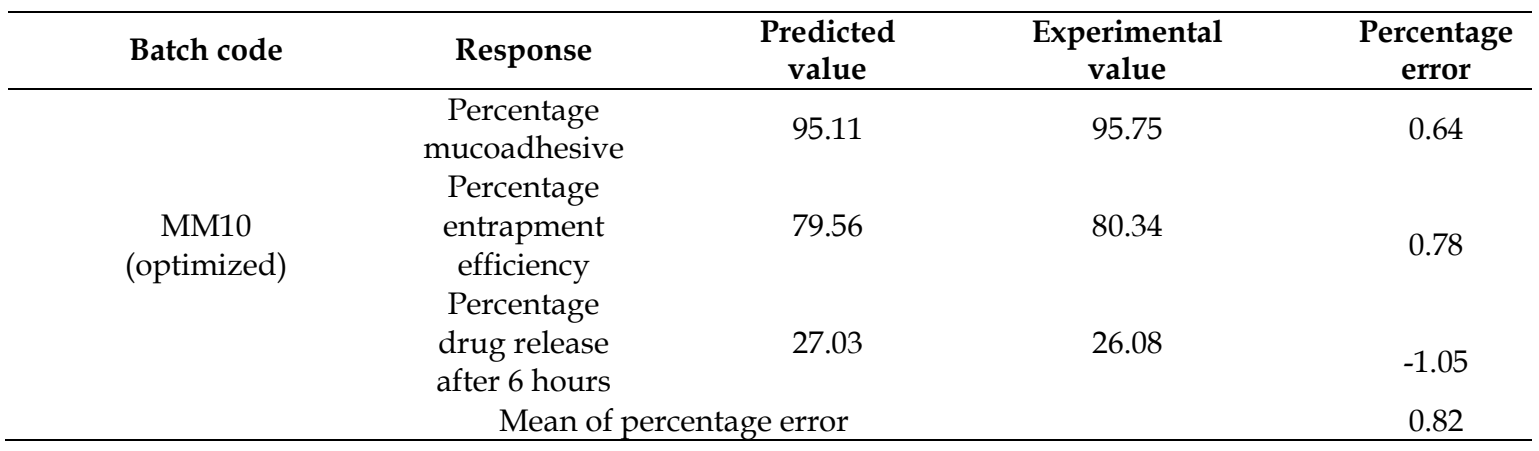

\subsection{Surface morphology}

The morphology of the optimized microspheres was examined using scanning electron microscopy. The view of the microspheres showed a spherical structure with a smooth surface morphology and within batches exhibited a range of sizes of microspheres (Figure 7).

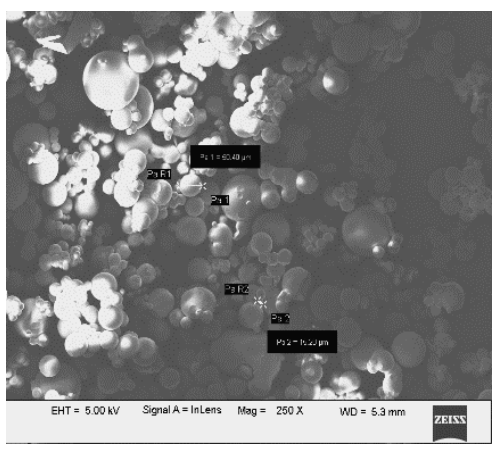

Figure 7. Scanning electron microscopy of MM10 (optimized formulation).

\subsection{Kinetic studies}

Calculated regression co-efficient for optimized formulation are shown in Table 7. These values of in vitro were attempted to fit into various mathematical models, zero order, first order, higuchi matrix and peppas.

These values were compared with each other for model fitting equation. Based on the highest regression values (r), the best fit model was Korsmeyer and Peppas. 
Further Korsmeyer and Peppas equation resulted into the values of $n>0.89$ indicating that the release from the optimized captopril mucoadhesive microspheres was by super Case II transport. This model is used to analyse the release of pharmaceutical dosage forms when the release mechanism is dominated by the swelling of the polymer.

Table 7. Kinetics release study of MM10 (optimized formulation).

\begin{tabular}{ccccccc}
\hline $\begin{array}{c}\text { Formulation } \\
\text { Code }\end{array}$ & $\begin{array}{c}\text { Zero } \\
\text { Order }\end{array}$ & $\begin{array}{c}\text { First } \\
\text { Order }\end{array}$ & Higuchi & $\begin{array}{c}\text { Peppas } \\
\text { Plot }\end{array}$ & $\begin{array}{c}\text { n- } \\
\text { Value }\end{array}$ & Best fit model \\
\hline $\begin{array}{c}\text { MM10 } \\
\text { (optimized) }\end{array}$ & 0.942 & 0.938 & 0.805 & 0.812 & 0.960 & $\begin{array}{c}\text { Zero order } \\
\text { Peppas } \\
\text { (Case II } \\
\text { transport) }\end{array}$ \\
\hline
\end{tabular}

\section{CONCLUSION}

The mucoadhesive drug delivery system is a promising approach to achieve controlled release using polymers like sodium alginate. The present study of captopril gastro retentive mucoadhesive microspheres, proved to be an ideal formulation as it released the drug in controlled fashion for extended period of time and thereby improving the bioavailability of captopril. It was observed that as the concentration of polymer increased, the entrapment efficiency and drug release decreased whereas percentage mucoadhesive increased. The optimized formulation with polymer concentration of $3 \%$ and stirring speed $1250 \mathrm{rpm}$ showed better release profile and therefore can be considered as the best formulation.

\section{MATERIALS AND METHODS}

Captopril and sodium alginate was provided by Yarrow Chemicals Ltd., Mumbai, India. All other chemicals/reagents used were of analytical grade.

\subsection{Compatibility studies}

The pure drug, polymer mix and formulation were subjected to Fourier transform infrared (FTIR) studies. The pure drug, polymer and formulation was mixed with small quantity of IR grade potassium bromide and scanned in the range of $4000-400 \mathrm{~cm}^{-1}$ using an FTIR JASCO instrument (Jasco Corporation, Tokyo, Japan) [8].

\subsection{Formulation of captopril mucoadhesive microspheres}

Microspheres containing captopril a core material were prepared by emulsification method. In the preliminary trials, weighed amount of captopril $(50 \mathrm{mg})$ was dispersed in aqueous solution of sodium alginate $(10 \mathrm{ml})$. The aqueous phase was emulsified in light liquid paraffin in the ratio 1:10 containing 2\% (v/v) Span 80 using a mechanical stirrer at $1500 \mathrm{rpm}$ for $60 \mathrm{~min}$. Five milliliters of $10 \% \mathrm{w} / \mathrm{v}$ calcium chloride dissolved in a mixture of methanol and isopropanol in a ratio of 2:3 was added slowly to the emulsion and stirred to assure efficient cross-linking. Microspheres were collected by filtration, washed with isopropanol thrice, and finally air-dried at room temperature. M1 to M4 were the preliminary batches prepared using different levels of sodium alginate $(1,2,3$ and $4 \%)$ [9].

\subsection{Experimental design}

The design of experiments (DOE) was used to optimize the emulsification method with the minimum number of experiment runs and to find out which process variables have the highest impact on the prepared microspheres. In this study, central composite design was applied. On the basis of preliminary trials, concentration of sodium alginate and stirring speed were used as independent variables whereas drug entrapment efficiency, percentage mucoadhesive and in vitro drug release after 6 hours were selected as dependent variables. Formulations MM1 to MM9 were prepared using three different levels of sodium alginate concentration and stirring speed. The full factorial experimental design lay out is given in Table 8 . The polynomial equations were generated for each responses using design expert software (version 11.00) and intensive grid search was performed over the experimental domain to get optimum formulation (MM10). Optimized formulation was then formulated and used to validate the obtained polynomial equation model [10]. 
Table 8. Full factorial experimental design layout.

\begin{tabular}{ccc}
\hline $\begin{array}{c}\text { Batch } \\
\text { (runs) }\end{array}$ & $\begin{array}{c}\text { Factor 1 } \\
\text { Concentration of sodium alginate(A) }\end{array}$ & $\begin{array}{c}\text { Factor 2 } \\
\text { Stirring speed (B) }\end{array}$ \\
\hline MM 1 & 0 & 0 \\
MM 2 & -1 & 0 \\
MM 3 & 1 & 0 \\
MM 4 & 0 & 1 \\
MM 5 & 1 & 1 \\
MM 6 & -1 & 1 \\
MM 7 & 0 & -1 \\
MM 8 & -1 & -1 \\
MM 9 & 1 & -1 \\
& & \\
\hline Code & Concentration of sodium alginate (\% w/v) & Stirring speed (rpm) \\
\hline-1 & 2.5 & 1000 \\
0 & 3 & 1500 \\
1 & 3.5 & 2000 \\
\hline
\end{tabular}

\subsection{Regression analysis}

The targeted response parameters were analysed statistically by applying Analysis of Variance (ANOVA) using Design Expert Software (version 11.00). For all the response variables statistical second -order model including interaction and polynomial terms were generated using Multiple Linear Regression Analysis (MLRA). The general form of the model is represented as:

$$
Y=\beta 0+\beta 1 A+\beta 2 B+\beta 3 A B+\beta 4 A^{2}+\beta 5 B^{2}+\beta 6 A^{2}+\beta 7 A^{2} B+\beta 8 A^{2} B^{2}
$$

Where $\beta 0$, is the intercept which is the arithmetic average of all quantities of outcomes for 9 runs, $\beta 1$ to $\beta 8$ are the coefficients computed from the observed experimental values of Y. A and B are the coded levels of the independent variables. $\mathrm{AB}$ is the interaction between the main effects. $\mathrm{A}^{2}$ and $\mathrm{B}^{2}$ are the quadratic terms of the independent variables that were used to simulate the curvature of the designed sample space. The quadratic models generated by regression analysis were used to construct the 3- dimensional graphs. The effect of the independent variables on each response parameter was visualized from the contour plots [11].

\subsection{Evaluation of captopril mucoadhesive microspheres}

\subsubsection{Percentage yield}

The percentage yield of all the formulations was determined by weighing the microspheres after drying. The percentage yield of different formulations was calculated as follows [12]:

$\%$ Yield $=\frac{\text { Actual weight of microsphere }}{\text { Total weight of drug and polymer }} \times 100$

\subsubsection{Micromeritic studies}

Particle size analysis:

Particle sizes of all the formulations were determined by optical microscopy with the help of ocular and stage micrometer. Sizes of around 100 particles were measured, and their average particle size was determined. The mean particle size of all formulations was determined by using the Edmondson's equation $[13,14]$ :

$$
\text { D mean }=\frac{\Sigma \text { nd }}{\Sigma \mathrm{n}}
$$

Where, $\mathrm{n}=$ number of microspheres checked; $\mathrm{d}=$ mean size range.

Bulk density:

The prepared microspheres was weighed and introduced into a graduated measuring cylinder of $10 \mathrm{ml}$ capacity. The volume of the sample was taken, and bulk density was calculated using the formula given below $[13,14]$ : 
Bulk density $=\frac{\text { Weight of the microsphere }}{\text { Bulk volume of the microsphere }}$

\section{Tapped density:}

The prepared microspheres was weighed and introduced into a graduated measuring cylinder of $10 \mathrm{ml}$ capacity. The initial volume was noted and the cylinder was allowed to fall under on to a hard surface from the height of $2.5 \mathrm{~cm}$ at 2-second intervals. Tapping was continued until no further change in volume was noted $[13,14]$.

$$
\text { Bulk density }=\frac{\text { Weight of the microsphere }}{\text { Volume of the microsphere after tapping }}
$$

\section{Carr's Compressibility Index:}

The percentage compressibility index was calculated according to the following formula $[13,14]$ :

$$
\% \text { Compressibility Index }=\frac{\text { Tapped density-Bulk density }}{\text { Tapped density }} \times 100
$$

\section{Hausner's ratio:}

Hausner's ratio of microspheres was determined by comparing the tapped density to the bulk density using the following formula $[13,14]$ :

$$
\text { Hausner's ratio }=\frac{\text { Tapped density }}{\text { Bulk density }}
$$

\section{Angle of Repose:}

It was determined fixed funnel method whose tip was fixed at a constant height (h) of $2 \mathrm{~cm}$ from the horizontal surface. The microspheres were allowed to freely pass through the funnel until the tip of the pile touches the tip of the funnel. The radius of the base of the pile was measured $(\mathrm{r} \mathrm{cm})$. The angle of repose was determined using the formula $[13,14]$ :

$$
\text { Angle of repose }=\tan ^{-1} \frac{\mathrm{h}}{\mathrm{r}}
$$

\subsubsection{Percentage mucoadhesive}

A freshly excised piece of intestinal segment from rat was mounted on to glass slides. A weighed amount of microsphere sample was added over a fresh rat intestinal segment, mounted on a tilted glass slide with an angle of 45 degree and allowed to rest for 3 hour. The effluent was run over the intestinal segment. The effluent was collected in a whattman filter paper and weight of detached microsphere particles was determined. By using the following equation percentage mucoadhesive can be calculated [15] (Figure 8). To carry out the procedure on rat intestinal segment approval was given by Institutional Animal Ethics Committee (IAEC) of Shree Devi College of Pharmacy:

$$
\text { Percentage mucoadhesive }=\frac{\text { Weight of sample-Weight ofdetached particles }}{\text { Weight of sample }} \times 100
$$

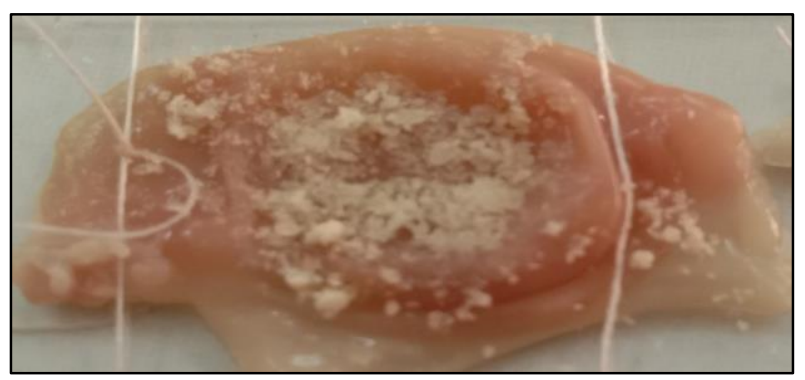

Figure 8. Percentage mucoadhesive test using fresh rat intestinal segment. 


\subsubsection{Drug entrapment efficiency}

Microspheres equivalent to $10 \mathrm{mg}$ of captopril were accurately weighed, triturated and digested in 10 $\mathrm{ml}$ simulated gastric fluid $(\mathrm{pH}$ 1.2)and kept overnight for extraction of drug. The digested homogenate was centrifuged and supernatant was collected. After appropriate dilution of supernatant with same buffer solutions, aliquots were assayed by UV spectrophotometer at $\lambda \max 211 \mathrm{~nm}$. Corresponding drug concentrations in the sample was calculated from the standard calibration curve.

Efficiency of drug entrapment for each formulation was calculated in terms of percentage drug entrapment as per the following formula [16,17]:

$$
\text { Drug Entrapment efficiency }=\frac{\text { Practical Drug Content }(\mathrm{mg})}{\text { Theoretical Drug Content }(\mathrm{mg})} \times 100
$$

The theoretical drug content was determined by calculation assuming that that the entire drug present in the solution gets entrapped in microspheres and no loss occurs at any stage of preparation of microspheres.

\subsubsection{In vitro drug release studies}

The dissolution studies of captopril mucoadhesive microspheres (equivalent to $50 \mathrm{mg}$ of captopril) were carried out using USP dissolution type I apparatus (basket type) and $900 \mathrm{ml}$ of simulated gastric fluid ( $\mathrm{pH} 1.2$ ), maintained at $37 \pm 0.5^{\circ} \mathrm{C}$. The speed of stirrer was maintained at $100 \mathrm{rpm}$. An aliquot of $5 \mathrm{ml}$ of the solution was withdrawn at predetermined time intervals, and replaced by an equivalent volume of fresh dissolution medium to maintain perfect sink condition. The sample solution was filtered through whatman No.1 filter paper and analyzed to determine the amount of drug releasedusing a UV spectrophotometer (UV 1800, Shimadzu, Kyoto, Japan) at $211 \mathrm{~nm}$ wavelength. All experiments were performed in triplicate and average values were plotted $[18,19]$.

\subsection{Optimized captopril mucoadhesive microspheres}

To obtain the desired response, numerical optimization using the desirability approach was employed to locate the optimal settings of the formulation variables. By setting constraints on the dependent and independent variables, the optimized formulation (MM10) was developed. The optimized formulation was evaluated for the responses [20].

\subsection{Evaluation of the optimized captopril mucoadhesive microspheres}

Prepared optimized captopril mucoadhesive microspheres were evaluated for percentage yield, micromeritic studies, percentage mucoadhesive, drug content, drug entrapment efficiency and in vitro drug release studies.

\subsection{Surface morphology}

Scanning electron microscopy was used to study surface topography, texture and to examine the morphology of fractured or sectioned surface of the mucoadhesive microspheres. The optimized formulation were mounted using a double-sided sticking tape and coated with gold (200 Ao) on the scanning electron microscopy (SEM) sample stab, under reduced pressure (0.001 torr) for $5 \mathrm{~min}$ using ion sputtering device (Jeol JFC-1100E, Tokyo, Japan). The gold-coated samples were observed under the scanning electron microscopy (SEM-Jeol JSM-840A, Tokyo, Japan) and photomicrographs of suitable magnification were obtained [21,22].

\subsection{Kinetic studies}

The in vitro drug release data of the optimized formulation was evaluated to check the goodness of fit to the zero-order kinetics, first-order kinetics, higuchi's model and Korsmeyer-Peppas model for quantifying the phenomena controlling the release from mucoadhesive microspheres [23].

Author contributions: Concept - A.S., P.S.; Design - A.S., P.S.; Supervision - A.S.; Resources - A.S, P.S; Materials -P.S.; Data Collection and/or Processing - A.S., P.S. S.S., C.S.; Analysis and/or Interpretation - A.S., P.S., S.S.; Literature Search - A.S., S.S., C.S.; Writing - A.S., C.S.; Critical Reviews - A.S., P.S., S.S., C.S.

Conflict of interest statement: The authors declared no conflict of interest. 


\section{REFERENCES}

[1] Patil AS, Dandagi PM, Masthiholimath VS, Gadad AP, Najwade BK. Development and characterization of chronomodulated drug delivery system of captopril. Int J Pharma Investig. 2011; 1(4): 227-233.

[2] White WB. Clinical assessment of early morning blood pressure in patients with hypertension. Prev Cardiol. 2007; 10: 210-214. [CrossRef]

[3] Wilding IR, Davis SS, Bakhshaee M, Stevens HN, Sparrow RA, Brennan J. Gastrointestinal transit and systemic absorption of captopril from a pulsed release formulation. Pharm Res. 1992; 9(5): 654-660. [CrossRef]

[4] Abbasi S, Yousef G, Ansari AA, Samani SM. Formulation and in vitro evaluation of a fast-disintegrating/sustained dual release bucoadhesive bilayer tablet of captopril for treatment of hypertension crises. Res Pharm Sci. 2016; 11(4): 274-283.

[5] Shadab M, Ahuja A, Khar R, Baboota S, Chuttani K, Mishra AK et al. Gastroretentive drug delivery system of acyclovir-loaded alginate mucoadhesive microspheres: formulation and evaluation. Drug Deliv. 2011; 18(4): 255-264. [CrossRef]

[6] Sawant K, Patel M, Patel J, Mundada P. Formulation, optimization, characterization and in vivo anti-ulcer activity of esomeprazole magnesium trihydrate gastro-resistant microspheres. Int J Pharm Pharm Sci. 2014; 6(9): 198-204. [CrossRef]

[7] Garud A, Garud N. Formulation of mucoadhesive microspheres of rosiglitazone maleate and it's in vitro evaluation using ionotropic gelation technique. Ars Pharm. 2015; 56(2): 101-107. [CrossRef]

[8] Katewongsa P, Lertsuphotvanit N, Phaechamud T. Cetirizine dihydrochloride/ $\beta$-cyclodextrin inclusion complex by ethanol kneading for taste masking. Indian J Pharm Sci. 2017; 79(5): 758-767. [CrossRef]

[9] Shadab M, Ahuja A, Khar R, Baboota S, Chuttani K, Mishra AK et al. Gastroretentive drug delivery system of acyclovir-loaded alginate mucoadhesive microspheres: formulation and evaluation. Drug Deliv. 2011; 18(4): 255-264. [CrossRef]

[10] Akhtar N, Pathak K. Cavamax W7 composite ethosomal gel of clotrimazole for improved topical delivery: development and comparison with ethosomal gel. AAPS PharmSciTech. 2012; 13(1): 344-355. [CrossRef]

[11] Sindhumol PG, Sudhakaran CR. Formulation and optimization of floating microspheres of cefixime trihydrate by factorial design. IJPRS. 2018; 7(1): 55-71. [CrossRef]

[12] Madhavi M, Madhavi K, Jithan AV. Preparation and in vitro/in vivo characterization of curcumin microspheres intended to treat colon cancer. J Pharm Bioallied Sci. 2012; 4(2): 164-171. [CrossRef]

[13] Abbas Z, Marihal S. Gellan gum-based mucoadhesive microspheres of almotriptan for nasal administration: formulation optimization using factorial design, characterization, and in vitro evaluation. J Pharm Bioallied Sci. 2004; 6(4): 267-277. [CrossRef]

[14] Dandagi PM, Mastiholimath VS, Gadad AP, Iliger SR. Mucoadhesive microspheres of propranolol hydrochloride for nasal delivery. Indian J Pharm Sci. 2007; 69(3): 402-407.

[15] Verma S, Kumar V, Jyoti, Mishra DN. Formulation, evaluation and optimization of mucoadhesive microspheres of acyclovir. Bull Pharm Res. 2014; 4(1): 14-20.

[16] Yerragunta B, Jogala S, Chinnala KM, Aukunuru J. Development of a novel 3-month drug releasing risperidone microspheres. J Pharm Bioallied Sci. 2015; 7(1): 37-44. [CrossRef]

[17] Dey S, Pramanik S, Malgope A. Formulation and optimization of sustained release stavudine microspheres using response surface methodology. ISRN Pharm. 2011: 627623. [CrossRef]

[18] Sahoo SK, Mallick AA, Barik BB, Senapati PC. Formulation and in vitro evaluation of Eudragit ${ }^{\circledR}$ microspheres of stavudine. Trop J Pharm Res. 2005; 4(1): 369-375. [CrossRef]

[19] Prasanthi D, Yanmanagandla D, Sripada RD. Formulation and evaluation of linagliptin mucoadhesive microspheres. Int Res J Pharm. 2018; 9(5): 11-17. [CrossRef]

[20] Shivakumar HN, Patel R, Desai BG. Formulation optimization of propranolol hydrochloride microcapsules employing central composite design. Indian J Pharm Sci. 2008; 70(3): 408-413.

[21] Crcarevska MS, Dodov MG, Goracinova K. Chitosan coated Ca-alginate microparticles loaded with budesonide for delivery to the inflamed colonic mucosa. Eur J Pharm Biopharm. 2008; 68(3): 565-578. [CrossRef]

[22] Ige P, Agrawal K, Patil U. Enhanced in vitro dissolution of iloperidone using caesalpinia pulcherrima mucoadhesive microspheres. Beni-Univ J Basic Appl Sci. 2015; 4(1): 26-32. [CrossRef] 
[23] Gaur PK, Mishra S, Kumar A, Panda BP. Development and optimization of gastroretentive mucoadhesive microspheres of gabapentin by Box-Behnken design. Artif Cells Nanomed Biotechnol. 2014; 42(3): 167-177. [CrossRef]

This is an open access article which is publicly available on our journal's website under Institutional Repository at http://dspace.marmara.edu.tr. 